\title{
The Usages of “Ji (几)” in Yulin Dialect
}

\author{
LIANG Qing \\ Minzu University of China, Beijing, 100081, China
}

\begin{abstract}
In Yulin dialect, there are three usages of “ji (几)”: interrogative pronouns, numerals, and degree adverbs. When used as an interrogative pronoun, it is generally used to inquire about the number and degree where the inquiry number is generally small, but the number can be large when it is used in asking about age. When used as a number, it can represent not only integers between one and ten, but also decimal part. When used as a degree adverb, there are rich syntactic formats such as “ji (几) + verb”, “ji (几) + adjective”, different formats indicating different meanings. Compared with Mandarin, the usage of Yulin dialect “ji (几)” is more diverse. We also analyze the use of “ji (几)" from a diachronic perspective and finally we propose that due to the reanalysis of the syntactic format and the change of semantics, the “ji (几)" is further grammaticalized from interrogative pronoun to degree adverb.
\end{abstract}

Keywords: Yulin dialect, degree adverb, interrogative pronoun, numeral, grammaticalization

\section{Introduction}

Yulin City (玉林市) is located in the southeast of Guangxi Zhuang Autonomous Region, bordering Maoming City (茂名市) in the east, Qinzhou City (钦州市) in the west, Beihai City (北海市) in the south, and Guigang City (贵港市) in the north. The dialects of Yulin City mainly include Cantonese dialects, Min dialects, and Hakka dialects. According to Atlas of Chinese Language, the Yulin dialect belongs to the Cantonese dialect. This article discusses the vernacular of Maijiu (卖酒) town. The Maijiu (卖酒) town is located in the north of Yulin City, and the domestic dialect belongs to Cantonese dialect.

Regarding the interpretation of “ji (几)”, Modern Chinese Dictionary lists two meanings: (1) interrogative pronoun, the number of inquiries (the estimated number is not too large); (2) numeral, means a number greater than one but less than 10. Great Chinese Dictionary contains four meanings: (1) number, and how many; (2) what; (3) how; (4) indicates a small number of uncertainties. The two professional dictionaries mainly explain the usage of "ji (几)" as a number of words and interrogative pronouns, but neither of them refers to the degree of adverbs.

“Ji (几)”, read [tci] (上声) in Mandarin, and read [ki] (阴上声) in Yulin dialect. This reflects Jian (见) [k], Qi (溪) $\left[\mathrm{k}^{\mathrm{h}}\right.$ ], Xiao (晓) $[\mathrm{x}]$ which is not fully differentiated into [tc], [t $\left.{ }^{\mathrm{h}}\right]$, [6]. The paper mainly analyzes the usage of "ji (几)" in Yulin dialect, and tries to explore the special features and reasons of the "ji (几)" usage.

LIANG Qing, Ph.D. student, research interests: Chinese language history and Chinese dialects, School of Literature and Journalism and Communication, Minzu University of China, Beijing, China. 


\section{The Usages of “Ji (几)”}

The “ji (几)” in Yulin dialect can be used as interrogative pronouns, numerals, and degree adverbs, which is equivalent to “duoshao (多少), duome (多么), duo (多), feichang (非常)” in Mandarin.

\section{Used as an Interrogative Pronoun}

“Ji (几)” is used to ask for the quantity, which is equivalent to the “duoshao (多少)” of Mandarin. This usage existed in ancient Chinese, but still be used in Yulin dialect

Example (1) 你 来几日了?

Ni lai ji ri le?

How many days have you been here?

“Ji (几)” can be directly added after the inquiry, that is, “ji (几) + noun”, such as “ji (几) + yinzhi (银纸)”, but such expression is rare. Instead, the "ji (几) + quantifier + noun” is generally used to ask about the quantity.

In ancient Chinese, “ji (几)" is generally used in querying the number between two and nine, that is, “ji (几)” is used for a small number. The Yulin dialect also retains this usage. However, it is worth noting that when used in age, the number can be both less and more than 10 .

Example (2) 个只侬几岁了?

Ge zhi nong ji sui le?

How old is this child?

Example (3) 外婆 几岁了?

Waipo ji sui le?

How old is the grandmother?

The "ji (几)" of Yulin dialect can be used to ask the age of a child, or to ask an elderly person, which is different from Mandarin.

“Ji (几)” is used to ask about the degree, which is equivalent to “duo (多)” in Mandarin. For example: “ji (几) + adjective” which is used in interrogative sentences to ask about degree, mostly in monosyllabic adjectives. If it is used as a predicate component, add “you (有)" in front of “ji (几)”.

Example (4) 几久布见你了?

Ji jiu mao jian ni le?

How long has it been since I saw you?

Here, “jiu (久)” is used as an adjective and “ji (几) + jiu (久)” is used to ask about how long, but in fact it means time is too long, for which we think that “ji (几)” is used to ask about degree.

\section{Used as a Numeral}

When “ ji (几)” is used as a numeral, it means an approximate number; the number referred to is limited to a number between two and nine; it is also used in combination with other numerals.

Ji (几) + quantifier. The number indicated by “ji (几)” is uncertain and is limited to numbers between two and nine.

Example (5) 台上有几本书。

Tai shang you ji ben shu.

There are several books on the table. 
When the number is expected to be small and not specified, the "ji (几)" is often used to indicate the rough estimate.

Quantifier + ji (几). It represents a slightly larger number than one and less than two. The quantifiers are generally time quantifiers, metrics, etc., and “ji (几)” is limited to single digits less than 10 . If the quantifier is sui (岁), nian (年), wen (文), jin (斤), chi (尺), mi (米), etc., it can be said to be “sui ji (岁几), nian ji (年几), wen ji (文几), jin ji (斤几), chi ji (尺几), mi ji (米几)” where they refer to quantities that are slightly larger than one.

Example (6) 个只侬岁几了。

Ge zhi nong sui ji le.

This child is a little older than one year old.

It means that this child is more than one year old, but not more than two years old.

Numeral + ji (几) + quantifier. This represents an indeterminate number. The numeral is an integer of 10 or more; “ji (几)” means an integer and indeterminate number no more than 10 , which is equivalent to "duo (多)” in Mandarin.

\section{Example (7) 我养了百几只鸡儿。 \\ Wo yang le bai ji zhi ji-er. \\ I have raised more than 100 chickens.}

Numeral + quantifier + ji (几). This represents an indeterminate number which can be single digits, tens digits, or multiple digits; quantifiers are mainly quantifiers, metrics, etc.; “ji (几)” means uncertain numbers that less than one digit, similar to “duo (多)" of Mandarin.

Example (8) 爸六点几 钟回。

Ba liu dian ji zhong hui.

Dad will come back at later than six o'clock.

\section{Used as a Degree Adverb}

“Ji (几)” is often used as a degree adverb in Yulin dialect, which is equivalent to “duome (多么), hen (很)” in Mandarin.

Ji (几) + adjective/verb. “Ji (几)” means a high degree, and can also take modal particles at the end of the sentence which is often used in exclamatory sentences expressing an exaggerated tone. It has subjective evaluations, but may not match the facts.

Example (9) 你 有 知 佢 有几伤心。

Ni mao zhi qu you ji shangxin.

You can’t imagine how sad he is.

Example (10) 你细妹 溜 几 快。

Ni ximei liu ji kuai.

Your sister is running really fast.

“Ji (几) + adjective/verb” is also a high degree expression, equivalent to the “hen (很), feichang (非常)” of Mandarin, with an emphasis on objective description. General adjectives can enter the structure, such as white, red, black, hunger, full, wide, high, long, thin, fat, hot, cool, quiet, generous, slim, active, careful, serious, ignorant, etc. 
Example (11) 个只侬几懒。

Ge zhi nong ji lan.

This child is very lazy.

This sentence indicates that "child's laziness" is an objective fact that does not include the speaker's subjective evaluation and feelings.

Ji (几) + verb + de (得). The verbs entering the structure are mainly monosyllabic verbs, such as “eat, drink, sleep, sit, talk, speak, read, learn, cry, laugh, run, walk, jump”, and so on.

Example (12) 饮 完 水酒, 佢 就几倾得。

Yin wan shuijiu, qu jiu ji qing de.

He was especially able to talk after drinking.

Ji (几) + adjective + dou (都). “Ji (几)" means a certain degree, the meaning of which is similar to the “Wulun (无论) ... dou (都) ...” of Mandarin. “Dou (都)” is often followed by “zhe (着)” and “yao (要)”; “ji (几) + adjective + dou (都) + zhe (着)” means that the speaker must do this; “ji (几) + adjective + dou (都) + yao (要)” indicates that the speaker is willing to do so.

Example (13) 书几难都着读。

Shu ji nan dou zhe du.

No matter how difficult, you must study.

Example (14) 几高我都要爬上去。

Ji gao wo dou yao pa shangqu.

No matter how high, I want to climb up.

Yao (要) + ji (几) + adjective, jiuyou (就有) + ji (几) + adjective. This is a commonly used format for Yulin dialect and usually contains exaggerated ingredients. “Ji (几)” also means a certain degree.

Example (15) 要 几 热闹, 就有几 热闹。

Yao ji re'nao, jiuyou ji re'nao.

This is extremely lively.

In summary, it mainly discusses the usage of the "ji (几)” as interrogative pronouns, numerals, and degree adverbs in Yulin dialect. The use of "ji (几)" in inquiring about number has existed in ancient times. “Ji (几) + adjective” asks the degree in the interrogative sentence and expresses a certain degree in the affirmative sentence which tends to be the side of high degree. "Ji (几)" is used in conjunction with quantifiers, numerals, etc., mainly to indicate the uncertain number. “Ji (几)" is often used as a degree adverb while "ji (几) + adjective/verb” has subtle differences. When “ji (几)” is equivalent to “duome (多么)”, it often contains the subjective emotion of the speaker, expressing the sigh of tone; when “ji (几)” is equivalent with “hen (很), feichang (非常)”, it focuses on objective descriptions, without subjective meaning. The difference between them is mainly due to the difference in tone when speaking.

\section{The Diachronic Development of “Ji (几)”}

By analyzing the usage of the Yulin dialect “ji (几)”, it is found that "ji (几)” can be used as an adverb indicating the degree. This is its special usage which is not contained in Mandarin. Dialect is the living fossil of ancient Chinese. The special language phenomenon in dialect may be the reservation of ancient Chinese, or it 
may be the inheritance and innovation of ancient Chinese. The following is a review of the development of " $\mathrm{ji}$ (几)” from the perspective of diachronic, and explores the source of the usage of "ji (几)" in Yulin dialect.

In the period of ancient Chinese and medieval Chinese, “ji (几)” was used as interrogative pronouns and numerals. When used as an interrogative pronoun, “ji (几)” is often used in conjunction with "he (何)”.

Example (16) 人 寿 几 何? (《左传》)

Ren shou ji he? (Zuo Zhuan)

How long is the life of a person?

“Ji (几)” is used as a number, followed by “shi (十), bai (百), qian (千), wan (万)”, etc., to represent the approximate number. It can be used to ask about the quantity without a quantifier.

Example (17) 其 文笔 几 百 余篇。(《魏书》)

Qi wenbi ji bai yu pian. (Wei Shu)

His articles have several hundreds.

Example (18) 帝 问 曰: “诸葛公 起居 何如, 食 可 几 米? ” (《晋书》)

Di wen yue: “Zhugegong qijun ruhe, shi ke ji mi?” (Jin Shu)

The emperor asked: "How is Zhugegong's life, how many rice does he eat?"

In (18), “mi (米)” is a noun, we can use "ji (几) + mi (米)” to express "how many rice”; such expression is different to "ji (几) + quantifier + noun”.

At the beginning, there was no limit to the number of "ji (几)" inquiries, but in the modern Chinese period, the number was generally not too large.

Example (19) 师问 僧: “你在这里得几年?”对云: “五六年。” (《祖堂集》)

Shi wen seng: “ni zai zheli de ji nian?” Dui yun: “wuliu nian.” (Zu Tang Ji)

The mage asked the monk: "How many years do you need to be here?” Replied: "five or six years."

It can be seen that the Yulin dialect inherits the use of interrogative pronouns and numerals in the ancient Chinese “ji (几)".

By consulting ancient books, we found that the degree of adverbs of “ji(几)” appeared in the Song Dynasty, such as:

Example (20) 几 伤心 桥 东片 月, 趁 夜 潮, 流恨 入 秦淮。(宋・赵希迈《八声甘州》)

Ji shangxin qiao dong qian yue, chen ye chao, liu hen ru qinhuai. (Song Zhao Ximai $B a$ Sheng Gan Zhou)

Example (21) 南岗北阜凭高地, 引首吴天几 怆神。(宋・陈造《寄乡中亲友》)

Nan gang bei fu ping gao di, yin shou wu dian ji chuangshen. (Song.Chen Zao Ji Xiang Zhong Qin You)

These two examples are from the poems of the Song Dynasty. In (20), the “ji (几) + shangxin (伤心)" can be understood as very sad. "Shangxin (伤心)" is an adjective, which means sad. “Ji (几)" is as a degree adverb to strengthen the degree of “shangxin (伤心)”. In (21), “ji (几)” also acts as a degree adverb.

How did the usage of the "ji (几)" as degree adverbs evolve?

We think that the use of "ji (几)" as degree adverbs evolved from interrogative pronouns. Ancient Chinese can use “ji (几) + noun” to ask the number. With the extensive use, the nouns after "ji (几)” gradually expand 
from general nouns to abstract nouns, such as “chou (愁), chouchang (惆怅), shangxin (伤心)”, and other emotional nouns, and such nouns also can often be understood as an adjective, which leads to a re-understanding of "ji (几) + noun/adjective”. The "ji (几)" can be regarded as interrogative pronouns of the inquiry number, or as adverbs for degree of adjectiveness. Because of the reinterpretation of the structure and the change of context, “ji (几)” gradually evolved from an interrogative pronoun to a degree adverb.

Therefore, this is the source of the usage of "ji (几)” as the adverbs of degree in Yulin dialect. The retention of this usage is the inheritance of the usage in ancient Chinese. Mandarin does not retain the usage of “ji (几)” as degree adverb. This is perhaps related to the strong collocation of Chinese "numeral/pronoun + quantifier + noun” which makes it impossible for Chinese to retain the usage of “ji (几) + noun”, thus interrupting the possibility of "ji (几)" continuing to develop adverbs of degree. Therefore, this may also explains why there are not many "ji (几)” as adverbs in Chinese history. However, the Yulin dialect still retains the phenomenon of "numeral/pronouns + nouns”, which provides the possibility and conditions for the "ji (几)” in the "ji (几) + noun” from the interrogative pronouns to degree adverbs. Also for this reason, the "ji (几)" in Yulin dialect is often used as an adverb of degree with diverse usages.

\section{Conclusion}

In the Yulin dialect, “ji (几)” is widely used not only as a number and interrogative pronoun, but also as a degree adverb. The article describes in detail the syntactic situation of the three usages of Yulin dialect, then discusses the historical situation of the usage of “ji (几)" from a diachronic perspective, and proposes that the use of degree adverbs of “ji (几)” evolved from interrogative pronouns, experiencing grammaticalization processes such as reanalysis of structures and re-understanding of semantics.

The use of "ji (几)” as degree adverbs is a feature of Yulin dialect. Its usage and evolution path deserve our attention.

\section{References}

Huang, Q. (2015). On the [ki] 几 in Zhaoping dialect of Guangxi Zhuang Autonomous Region. Dialect, (2), 159-163. Li, R. (2002). Comprehensive dictionary of regional dialects of modern Chinese. Nanjing: Jiangsu Education Press. Liang, Z. D. (2001). The pronouns of Yulin dialect. Journal of Yulin Normal University, 22(2), 80-83.

Luo, F. (2017). Adverbs of degree “ji” and “zhi” in Cantonese dialect. Journal of Qinzhou University, 32(2), 29-34.

Zeng, X. J. (2001). The degree adverbs “ji (几)” in Changsha dialect. Journal of Hunan First Normal University, (1), 32-35. 